\title{
Management and prophylaxis of bacterial and mycobacterial infections among lung transplant recipients
}

\author{
Koh Okamoto ${ }^{1}$, Carlos A. Q. Santos ${ }^{2}$ \\ ${ }^{1}$ Department of Infectious Diseases, University of Tokyo Hospital, Tokyo, Japan; ${ }^{2}$ Division of Infectious Diseases, Rush University Medical Center, \\ Chicago, IL, USA \\ Contributions: (I) Conception and design: All authors; (II) Administrative support: All authors; (III) Provision of study materials or patients: All \\ authors; (IV) Collection and assembly of data: All authors; (V) Data analysis and interpretation: All authors; (VI) Manuscript writing: All authors; (VII) \\ Final approval of manuscript: All authors. \\ Correspondence to: Koh Okamoto, MD, MS. Department of Infectious Diseases, University of Tokyo Hospital, Tokyo, Japan. \\ Email: kokamoto-tky@umin.ac.jp.
}

\begin{abstract}
Bacterial and mycobacterial infections are associated with morbidity and mortality in lung transplant recipients. Infectious complications are categorized by timing post-transplant: $<1,1-6$, and $>6$ months. The first month post-transplant is associated with the highest risk of infection. During this period, infections are most commonly healthcare-associated, and include infections related to surgical complications. The lungs and bloodstream are common sites of infections. Common healthcare-associated organisms include methicillin-resistant Staphylococcus aureus (MRSA), Gram-negative bacilli such as Pseudomonas aeruginosa, and Clostridioides difficile. More than 1-month post-transplant, opportunistic infections can occur. Tuberculosis occurs in $0.8-10 \%$ of lung transplant recipients which reflects variation in background prevalence. The majority of post-transplant tuberculosis stems from reactivation of untreated or undiagnosed latent tuberculosis. Most post-transplant tuberculosis occurs in the lungs and develops within a year of transplant. Non-tuberculous mycobacteria commonly colonize the lungs of lung transplant candidates and are often hard to eradicate even with prolonged courses of antimycobacterial agents. Drug interactions between antimycobacterial agents and calcineurin and mTOR inhibitors also complicates treatment post-transplant. Given that infection adversely impacts outcomes after lung transplant, and that anti-infective therapy is often less effective after transplant, infection prevention is key to long-term success. A comprehensive approach that includes pre-transplant evaluation, perioperative prophylaxis, longterm antimicrobial prophylaxis, immunization, and safer living at home and in the community, should be employed to minimize the risk of infection.
\end{abstract}

Keywords: Bacterial infection; mycobacterial infection; lung transplant; long-term management; prophylaxis

Submitted Dec 14, 2019. Accepted for publication Jan 15, 2020.

doi: $10.21037 /$ atm.2020.01.120

View this article at: http://dx.doi.org/10.21037/atm.2020.01.120

\section{Introduction}

After nearly a half century since the first lung transplant in 1963, the number of lung transplants performed worldwide has increased considerably and now approaches 6,000 transplants annually (1). While it is life-saving for patients with end stage lung disease, 5-year survival after lung transplant is still around $50 \%$ which is less than that of other solid organ transplants (2,3). Analysis of an international registry of 60,107 lung transplants performed between 1990 and 2016 showed that infection was the second most common cause of death after graft failure (2). It accounted for $16.5-36.8 \%$ of deaths depending on time from transplant and was highest (36.8\%) between 31 days to 1 year (2). Bacterial infections are most common (4). Improvement in management and prevention of bacterial infections is of paramount importance in the care of lung transplant 
recipients. In this review, we focus on bacterial and mycobacterial infections and emphasize their management and prevention in the long-term.

\section{Risk, type, and timing of infection}

The risk of infection for lung transplant recipients is largely affected by two major factors: net state of immunosuppression and epidemiologic risk factors (5). Factors contributing to the net state of immunosuppression include immunosuppressive therapy, prior therapies including chemotherapy and antimicrobials, mucocutaneous barrier integrity, neutropenia, technical complications, underlying immune defects, metabolic complications, and viral infections. In general, risk of rejection is highest in the early post-transplant period, thereby necessitating intense immunosuppressive therapy immediately posttransplant. Although lung transplant recipients require life-long immunosuppressive therapy, maintenance immunosuppression becomes less intense over time.

Lungs have direct contact with the environment and therefore are continuously exposed to various pathogens. After lung transplant, denervation of the allograft results in decreased mucociliary clearance and cough, leading to decreased local host defense mechanisms. In addition, although there is substantial variation among transplant centers, roughly a third of patients undergo lung transplant for interstitial lung disease, which often requires long-term immunosuppressive therapy even before transplant (2). Another fifth of patients have bronchiectasis as a primary indication, mostly cystic fibrosis (2). Since most patients with cystic fibrosis are colonized or infected with drug resistant Gram-negative bacteria, they often receive multiple courses of antibiotics pre-transplant. Important epidemiological exposures pertinent to bacterial and mycobacterial infections include donor-derived infections, recipient-derived infections, nosocomial infections, and community-acquired infections (6). Donor-derived and recipient-derived infections are now rare because of pretransplant screening, evaluation, and treatment of bacterial and mycobacterial infection. However, cases of donorderived pulmonary tuberculosis in lung transplant recipients have been reported (7-10).

The timing of post-solid organ transplant infection is often categorized into three different time periods by time from transplant; $<1,1-6$, and $>6$ months $(5,6)$. The first month post-transplant is associated with the highest risk of infection. During this period, infections are most commonly healthcare-associated, and include infections related to surgical complications. In addition, donorderived infections and preexisting recipient infections (recipient-derived infections) can occur. Among bacterial and mycobacterial pathogens, antimicrobial resistant species including methicillin-resistant Staphylococcus aureus (MRSA), Gram-negative bacilli such as Pseudomonas aeruginosa, and Clostridioides difficile are often involved. In patients with preexisting structural lung diseases like cystic fibrosis, glucose non-fermenting Gram-negative bacilli such as $P$. aeruginosa or Burkbolderia cepacia can be colonizers pre-transplant and often resistant to multiple agents. These organisms can be a culprit of infection early post-transplant. Between the first and sixth months after transplant, patients are at the highest risk of opportunistic infections. Prophylaxis with trimethoprim-sulfamethoxazole is used widely and has reduced the incidence Pneumocystis infection. Trimethoprim-sulfamethoxazole also has activity against Nocardia and Listeria monocytogenes. Nocardiosis and listeriosis can occur during and after this period especially without prophylaxis with trimethoprim-sulfamethoxazole. Similarly, infections from mycobacterial infections (both tuberculous and non-tuberculous infections) can occur during and after this period. After six months post-transplant, pneumonia from community-acquired pathogens, most commonly Streptococcus pneumoniae, become more important as immunosuppressive regimens are tapered and stable in most cases.

Although this schema of post-transplant infections is useful, variation exists in real-world clinical care. For instance, if a patient has protracted surgical complications, healthcare-acquired infections can occur after one month. If a patient has allograft rejection requiring augmentation of immunosuppression, the patient remains at high risk of opportunistic infections after six months post-transplant.

\section{Common sites of infections}

\section{Pneumonia}

Pneumonia remains the most frequent complication for lung transplant recipients, with about a third of recipients developing pneumonia post-transplant (11-14). Pneumonia is associated with significant mortality (13). Its incidence is highest in the first month and decreases gradually over time $(13,15)$. Pneumonia is predominantly from bacterial pathogens, especially Gram negative bacilli such as $P$. aeruginosa, Acinetobacter baumanii, and Enterobacteriaceae 
$(12,13,15-17)$. Differential diagnoses for post-transplant pneumonia is broad and includes infectious (bacterial, mycobacterial, fungal, viral, and parasitic) and noninfectious etiologies. A systematic approach to stratify risk and orient therapy is needed (18). Initial evaluation involves obtaining key clinical history such as recent hospitalizations and exposures, as well as laboratory and radiologic studies. Depending on the risk for opportunistic infections and severity of illness, additional studies such as sputum culture for bacterial and mycobacterial pathogens, interferon gamma releasing assay, Legionella antigen and tissue specimen testing may be performed to guide empiric and targeted therapy.

\section{Bacteremia}

The bloodstream is the second most common site of bacterial infection $(12,14)$. The lungs and vascular catheters are common sources (19). In addition to Gram-negative bacilli, Gram-positive cocci such as $S$. aureus, coagulase negative Staphylococcus, and Enterococcus can also cause bacteremia (20).

\section{Bacterial infections}

\section{Staphylococcus aureus}

S. aureus is an important pathogen in lung transplant recipients, and affects about a fifth of patients $(21,22)$. Of those, about $40 \%$ are methicillin-resistant (22). The respiratory system and bloodstream are the most common sites of infection (21-23). S. aureus infections are associated with increased mortality and graft rejection (22). Risk factors include isolation of MRSA from recipient's sterility cultures, and MRSA cultures from the nares or respiratory tract at the time of transplant (22). In light of the high prevalence of MRSA infections among lung transplant recipients, vancomycin is often used for perioperative prophylaxis (24). A computer simulation model study suggested that screening and decolonization of MRSA among lung transplant recipients would be cost-effective (25). However, further research is needed before active surveillance can be recommended (24). In the meantime: (I) adherence to hand hygiene among patients, families, and healthcare workers; (II) universal decolonization with chlorhexidine bathing for patients in intensive care units; (III) disinfection of patient equipment and the hospital environment are recommended to reduce MRSA transmission and infections (24).

\section{Pseudomonas aeruginosa}

P. aeruginosa is an important pathogen for lung transplant recipients because of its prevalence and tendency to develop drug resistance. It is a common colonizer seen in over $30 \%$ of lung transplant recipients and is the most common cause of post-transplant pneumonia accounting for a quarter of cases $(13,26)$. Pre-transplant colonization with $P$. aeruginosa is also common among patients with structural lung diseases, especially cystic fibrosis (27). Up to $45 \%$ of them are multidrug resistant strains (28). Post-transplant airway colonization with $P$. aeruginosa is associated with subsequent development of bronchiolitis obliterans syndrome, which is a major cause of death among lung transplant recipients $(26,27)$. Although post-transplant infections with multidrug resistant $P$. aeruginosa poses a significant challenge, survival rates are comparable regardless of its presence (29) and pretransplant colonization with multidrug resistant $P$. aeruginosa is not an absolute contraindication to transplant (30). If a transplant recipient has a history of $P$. aeruginosa colonization, at least two antipseudomonal agents based on previous antibiotic susceptibility results should be continued for 2 to 3 weeks post-transplant (31). Colistin and aminoglycosides are agents often used for prophylaxis and treatment of multidrug-resistant $P$. aeruginosa. However, they have cumulative nephrotoxicity especially with concomitant calcineurin inhibitor use. Newer agents such as ceftolozane-tazobactam or ceftazidime-avibactam might be options but their role in lung transplant recipients is yet to be defined $(32,33)$. Use of inhaled colistin and aminoglycosides as adjunctive therapy to intravenous agents for prophylaxis and treatment of post-transplant infection with multidrug resistant $P$. aeruginosa in lung transplant recipients has been reported in case series (34-36). However, more studies are needed to evaluate its efficacy and safety.

\section{Clostridioides difficile}

The incidence of $C$. difficile infection (CDI) in lung transplant recipients is $1.9-22.9 \%(37-43)$ and is highest of all solid organ transplant recipients $(44,45)$. Besides the early post-transplant period, CDI has a second peak after 24 months (42). CDI has been associated with increased mortality among lung transplant recipients $(37,42)$. The diagnosis and treatment of CDI are generally the same as non-transplant recipients (45). Details regarding management are available in guidelines (45). Reducing unnecessary antibiotic use through antimicrobial 
stewardship programs, decreasing use of gastric suppressing agents, avoiding prolonged hospitalization, and increasing adherence to contact precautions when necessary are recommended strategies for CDI prevention (45). The role and safety of probiotics have not been established in lung transplant recipients (46).

\section{Nocardia}

Nocardiosis is an important infection in lung transplant recipients. Nocardia species are found in soil, freshwater, saltwater, and decaying vegetation worldwide. There are more than 40 species that cause human infection that have unique geographic distributions and antimicrobial susceptibility patterns. The incidence of nocardiosis is $1.9-3.5 \%$ in lung transplant recipients which is highest of all solid organ recipients (47-49). In a retrospective study of 473 lung transplant recipients, nocardiosis occurred a median of 34 months post-transplant (50). Its incidence has decreased due to trimethoprim-sulfamethoxazole use intended as Pneumocystis prophylaxis (51); however, there are reports of breakthrough nocardiosis from isolates susceptible to trimethoprim-sulfamethoxazole (50). Subacute nodular or cavitary lung lesions are its most common manifestations. In addition, nocardiosis has a propensity to involve the central nervous system, typically in the form of single or multiple brain abscesses. Patients may or may not have neurological symptoms; therefore, radiographic evaluation of the brain is necessary if a patient has nocardiosis outside of the central nervous system. Skin and soft tissue infections, as well as disseminated infections have been described (49). The diagnosis of nocardiosis requires isolation of Nocardia from specimens obtained from suspected sites of infection. Because antimicrobial susceptibility is highly variable among species and isolates, isolation with accurate speciation of Nocardia is crucial. It is recommended that incubation be prolonged with selective media; that molecular methods are used for speciation; and that clinicians communicate with the clinical microbiology laboratory (52). The antimicrobial regimen depends on the susceptibility pattern of the causative isolate, as well as site and severity of infection. Trimethoprim-sulfamethoxazole is the agent of choice if the isolate is susceptible. Mild to moderate infections can be treated with trimethoprimsulfamethoxazole alone; in contrast, at least two agents (typically imipenem-cilastatin or amikacin in addition to trimethoprim-sulfamethoxazole) are required for severe infection, central nervous involvement or disseminated diseases (52). The recommended duration of therapy is 6-12 months or longer dependent on the site and extent of infection as well as the degree of immunosuppression (52). Trimethoprim-sulfamethoxazole may be useful for preventing primary and relapsed nocardiosis; however, the optimal dose and duration are not well defined (52).

\section{Mycobacterial infections}

\section{Tuberculosis}

The reported incidence of tuberculosis in lung transplant recipients is $0.8-10 \%(53-59)$, likely reflecting variation in background prevalence. In a Spanish multicenter study of 4,388 solid organ transplant recipients, lung transplant recipients were 5.6 and 73.3 times higher risk than other solid organ transplant recipients and the general population respectively (60). Most post-transplant active tuberculosis is reactivation of untreated or undiagnosed latent tuberculosis (61). Less than 5\% are donor-derived and very few constitute primary infection (61). Most post-transplant tuberculosis occurs in the lungs and develops within a year $(56,59,60)$. In cases of donor-derived tuberculosis, pulmonary tuberculosis develops within 3-6 months posttransplant (62). Diagnosis of active tuberculosis in lung transplant recipients is similar to non-transplant patients. Given that its clinical manifestations and radiographic findings are non-specific, a high index of suspicion coupled with additional invasive procedures to obtain specimens when necessary are needed. The treatment for active tuberculosis among lung transplant recipients is the same as non-transplant patients. Daily dosing is strongly recommended (61).

Screening and treatment of transplant candidates and donors are important. However, more than a half of transplant candidates who later develop tuberculosis might show anergic or negative responses to tuberculin skin testing (56). For lung transplant candidates with positive tuberculin skin tests or interferon gamma release assays, therapy for latent tuberculosis should be provided after active tuberculosis is ruled out. Lung transplant candidates who are at high epidemiologic risk, such as close contacts of persons with active tuberculosis and/or radiographic evidence of prior tuberculosis without adequate treatment, should be considered for latent tuberculosis therapy. Isoniazid for 9 months is the recommended regimen for latent tuberculosis in solid organ transplant candidates (61). One study involving 398 lung transplant candidates 
reported comparable safety and efficacy with a 3 -month regimen with isoniazid and rifampin (63).

\section{Non tuberculous mycobacteria (NTM)}

NTM infection is a unique challenge to lung transplant candidates and recipients for several reasons. First, structural lung disease, which can be the indication for lung transplant, is a risk factor for NTM infection (64). Second, NTM is often hard to eradicate even with prolonged courses of antimycobacterial agents. Furthermore, drug interactions between antimycobacterial agents and calcineurin and mTOR inhibitors are problematic posttransplant. Finally, pre-transplant colonization with NTM, especially Mycobacterium abscessus or Mycobacterium avium complex (MAC), is associated with NTM disease and increased mortality post-transplant (65).

The reported incidence of NTM infection is $0.46-8.0 \%$ in lung transplant recipients, and primarily involves the lungs $(55,57,66-68)$. Among NTM, MAC and M. abscessus are the most common (69). The isolation of NTM, most commonly MAC, M. abscessus, and M. gordonae posttransplant is much more common than actual infection and can be seen in up to $22.4 \%$ of lung transplant recipients (66). Lung transplant itself is the strongest risk factor for post-transplant NTM infections $(70,71)$. Other risk factors include African-American race and cytomegalovirus mismatch status (67). Up to $80 \%$ of NTM infections in lung transplant recipients involve the lungs and pleural spaces, followed by cutaneous/soft tissue and disseminated infections (72). In a cohort study of 34 solid organ transplant recipients (19 of 34 were lung transplant recipients) with post-transplant NTM infections, the median diagnosis from transplant was 8 months (71). Diagnosis of NTM infection requires fulfillment of clinical, radiographic, and microbiological criteria similar to non-transplant recipients (73). However, diagnosis is often not straightforward. NTM airway colonization is common, making it difficult to differentiate disease from colonization. Furthermore, common lung colonizers of immunocompetent patients, such as $M$. gordonae, can be a pathogen in lung transplant recipients. Indeed, isolation of the same species on multiple occasions is associated with treatment among lung transplant recipients (70).

Antimicrobial therapy for NTM infections in lung transplant recipients is extrapolated from that in nontransplant patients $(73,74)$. The regimen differs by species and generally consists of two to three or more drugs.
Details of antimicrobial therapy for NTM infections are beyond the scope of this review and readers are invited to review published guidelines $(73,75)$. Of note, rifabutin and azithromycin are preferred over other rifamycins and macrolides because of less drug-drug interactions with calcineurin/mTOR inhibitors through CYP3A4 (74). Treatment duration depends on extent of disease and clinical response, and is often prolonged. For pulmonary NTM infections, therapy is continued for at least 12 months after respiratory cultures become negative (74). Decreasing immunosuppression when feasible and surgery for localized disease are important adjunctive treatment (74).

To reduce the risk of post-transplant NTM infection and ensure antimicrobial regimen tolerability, it is recommended that lung transplant candidates be treated pre-transplant to eradicate NTM infection if possible, or at least reduce mycobacterial burden (74). In addition, bilateral lung transplant, and/or minimizing spillage of native lung contents into the pleural cavity are recommended (74). After lung transplant, rinsing fiberoptic endoscopes with tap water should be avoided (74). Lung transplant recipients should be advised to avoid hot tubs or exposure to soil, dust, and plant material after hospital discharge (74).

\section{Prevention}

Given that infection adversely impacts outcomes after lung transplant, and that anti-infective therapy is often less effective after transplant, infection prevention is vital to the care of lung transplant patients. Attention should be paid to multiple preventive strategies at time periods described below.

\section{Pre-transplant evaluation}

Pre-transplant evaluation to assess risk of infection for candidates and donors can prevent transmission of donorderived pathogens, reactivation of preexisting pathogens, and surgical site infections. Standard evaluation consists of obtaining (I) thorough history that includes underlying lung disease, prior treatment, prior infections and their treatment, comorbidities, places of travel/residence, occupation, and exposure to animal and environmental pathogens; (II) physical examinations; (III) standard blood, microbiological, and radiographic studies (76). Depending on the history, further studies may be warranted. As part of standard screening, tests for syphilis [fluorescent Treponema antibody absorption (FTA-ABS), T. pallidum particle agglutination (TPPA), T. pallidum enzyme immunoassay 
(TP-EIA), rapid plasma reagin (RPR), Venereal Disease Research Laboratory (VDRL)], and tuberculosis (either purified protein derivative or interferon gamma releasing assay) are recommended for transplant candidates and living donors (76). If either or both are reactive, a transplant candidate or donor needs to be assessed for latent or active infection and treated accordingly pre-transplant. Respiratory cultures pre-transplant can guide perioperative antimicrobial prophylaxis, especially for patients with cystic fibrosis who are well known to be colonized with multidrug resistant organisms. In particular, patients colonized with Burkholderia cepacia genomovar III (cenocepacia) are at increased risk for poor outcomes after lung transplant (57). Colonization or infection with Burkbolderia cepacia complex and $M$. abscessus are relative contraindications for lung transplant $(77,78)$. For deceased donors, respiratory cultures with bronchoscopy, as well as blood and urine cultures are also recommended (76).

\section{Perioperative prophylaxis}

Surgical site infections occur in $5-19 \%$ of lung transplant recipients (79-82), and can present as soft tissue infection, mediastinitis, and airway anastomosis infection (83). In addition, early post-transplant pneumonia is even more common $(79,84)$. Data to guide optimal perioperative prophylaxis to prevent surgical site infection in lung transplant recipients are scarce. Clinical practice guidelines for antimicrobial prophylaxis in surgery developed by the American Society of Health-System Pharmacists, the Infectious Diseases Society of America, the Surgical Infection Society, and the Society for Healthcare Epidemiology of America recommend first generation cephalosporins as agents of choice (85). However, Gram negative bacilli such as Pseudomonas, Burkbolderia, and Enterobacteriaceae as well as Staphylococcus and Enterococcus are common causative organisms for surgical site infection. Because of this, vancomycin plus a third generation cephalosporin or cefepime are often used (83). Patients allergic to penicillin can be given levofloxacin instead. Given that recipients or donors can be infected or colonized with drug resistant organisms pre-transplant, perioperative prophylaxis should be tailored according to their microbiology and risk factors for surgical site infection. Antibiotics must be administered within 60 minutes (120 minutes for vancomycin or levofloxacin) before the incision $(85,86)$. The optimal duration is yet to be defined but the guidelines from the American Society of
Transplantation recommend 48-72 hours (83).

\section{Long term prophylaxis}

Trimethoprim-sulfamethoxazole is recommended primarily for the prevention of Pneumocystis pneumonia and continued life-long for lung transplant recipients (87). Since it has activity against $S$. pneumoniae, Staphylococcus, Enterobacteriaceae, L. monocytogenes, and Nocardia, trimethoprim-sulfamethoxazole is useful for the prevention of bacterial infections. Breakthrough infections from these organisms have been reported (50). Of note, in cases where an antibiotic other than trimethoprim-sulfamethoxazole is used for the prevention of Pneumocystis pneumonia, antibacterial prophylaxis is not recommended. Therefore, clinicians should be aware of higher risk for infections from organisms typically covered by trimethoprimsulfamethoxazole.

\section{Immunization}

All lung transplant candidates should have up to date vaccinations according to national guidelines prior to transplant $(88,89)$. Because lung transplant recipients cannot mount an immune response to vaccination post-transplant due to immunosuppression, efforts should be made prior to transplant. The optimal immunization schedule for lung transplant candidates or recipients has not been studied; however, age, type of organ, and local epidemiology should be taken into account (90). Live-attenuated vaccines are not administered to lung transplant candidates receiving immunosuppressive medications and lung transplant recipients. Inactivated vaccines can be given pre-transplant and post-transplant. Live-attenuated and inactivated vaccines should be given at least 4 and 2 weeks prior to transplant to resolve vaccine-related viral replication and ensure adequate immune response respectively (88). The optimal time to restart immunization post-transplant is not well-defined; yet, immunization is typically restarted 3-6 months post-transplant provided there is no ongoing rejection and immunosuppression has stabilized. Vaccinations should not be withheld out of concern for allograft rejection if there is no ongoing rejection (88).

Regarding pneumococcal vaccination, both the 13 -valent protein-conjugate vaccine and the 23 -valent polysaccharide vaccine are indicated. If a lung transplant recipient has never received PCV13 or PPSV23, they can be given posttransplant. If a candidate or recipient has never received 
either vaccine, a single dose of PCV13 followed 8 weeks later by a PPSV23 is recommended pre-transplant in vaccine-naïve patients $(88,89)$. A PPSV23 booster can be given after 5 years.

Recommendations for vaccination of adult solid organ transplant candidates and recipients against bacterial pathogens from the American Society of Transplantation are summarized in Table 1 (89). If a lung transplant recipient plans for international travel, careful assessment and planning including risk-based immunization prior to travel is warranted (91).

Living donors should also be up to date with vaccinations according to national guidelines although vaccination for donors solely for the recipients' benefit is not recommended (88). Healthcare workers and close contacts of transplant recipients should also be vaccinated (88). In general, inactivated vaccines are preferred but live- attenuated vaccines can be given (except for oral polio and smallpox) as long as enhanced infection prevention precautions such as handwashing are performed.

\section{Safe living}

Most lung transplant recipients are at home and living with stable immunosuppressive regimens. While infections cannot always be avoided, practical advice can be given to patients when at home, work, or school. Infections 6 months post-transplant are often community-acquired; avoiding exposures is imperative. Key areas for prevention include infections transmitted by direct contact, droplet/ aerosol, ingestion, animal contact, sexual contact, and occupational exposure. Recommendations for safer living by solid organ transplant recipients from the American Society of Transplantation are summarized in Table 2 (92).

Table 1 Recommendations for vaccination of adult solid organ transplant candidates and recipients against bacterial pathogens from the American Society of Transplantation (89)

\begin{tabular}{|c|c|c|c|}
\hline & Live-attenuated or Inactivated & Before transplant & After transplant \\
\hline Pertussis (Tdap) & Inactivated & Recommended & Recommended \\
\hline Haemophilus influenzae type B & Inactivated & Recommended & Recommended \\
\hline Streptococcus pneumoniae (conjugate vaccine) & Inactivated & Recommended & Recommended \\
\hline BCG & Live attenuated & Recommended & Not recommended \\
\hline Anthrax & Inactivated & Not recommended & Not recommended \\
\hline
\end{tabular}

Table 2 Recommendations for safe living by solid organ transplant recipients with regards to prevention of bacterial and mycobacterial infections from the American Society of Transplantation (92)

\begin{tabular}{lll}
\hline Type of infection & Common causative organisms & Strategies \\
\hline $\begin{array}{l}\text { Infections transmitted } \\
\text { by direct contact }\end{array}$ & Clostridioides difficile & $\begin{array}{l}\text { Frequent and thorough handwashing especially when touching mucous } \\
\text { membranes }\end{array}$ \\
& Non tuberculous mycobacterium & Wear gloves whenever handling heavily contaminated materials \\
& Avoid going barefoot outside \\
& $\begin{array}{l}\text { Wear shoes, socks, long pants, and long-sleeved shirts while doing gardening, } \\
\text { yard work, farming, or being in parks or wooded areas }\end{array}$ \\
& Avoid self-piercing or tattooing or sharing of needles \\
\hline
\end{tabular}

Table 2 (continued) 
Table 2 (continued)

\begin{tabular}{|c|c|c|}
\hline Type of infection & Common causative organisms & Strategies \\
\hline \multirow{3}{*}{ Respiratory infections } & Pseudomonas aeruginosa & Avoid crowded areas \\
\hline & & Avoid tobacco or marijuana smoke \\
\hline & & $\begin{array}{l}\text { Avoid activities and occupational settings that increase the risk of exposure to } \\
\text { tuberculosis }\end{array}$ \\
\hline \multirow[t]{6}{*}{ Food safety } & Escherichia coli 0157:H7 & Avoid the following: \\
\hline & Salmonella & - Drinking unpasteurized milk, fruit, or vegetable juice/cider \\
\hline & Brucella & - Eating cheeses made with unpasteurized milk \\
\hline & & - Eating uncooked pate, meat spreads, cold cuts, and smoked seafood \\
\hline & & - Eating from public salad bars or buffets, street vendors, picnics \\
\hline & & - Eating any food prepared by someone with a recent diarrheal illness \\
\hline \multirow{4}{*}{$\begin{array}{l}\text { Animal contact related } \\
\text { infections }\end{array}$} & Enterobacteriaceae & Avoid contact with animals that have diarrhea \\
\hline & Chlamydophila & Take the pet regularly to the veterinarian for checkups \\
\hline & Pasteurella & Avoid cleaning bird cages, bird feeders, litter boxes, and handling animal feces \\
\hline & Capnocytophaga & Avoid stray animals \\
\hline $\begin{array}{l}\text { Sexually transmitted } \\
\text { infections }\end{array}$ & Chlamydia trachomatis & \\
\hline \multirow{5}{*}{$\begin{array}{l}\text { Work and school relat- } \\
\text { ed infections }\end{array}$} & & Seek guidance from transplant teams and/or transplant \\
\hline & & infectious disease consultants regarding the following: \\
\hline & & - The optimal timing of returning to work or school \\
\hline & & - Mitigating potential infectious risks in the workplace \\
\hline & & - Reported outbreaks of infections in the workplace or at school \\
\hline
\end{tabular}




\section{Conclusions}

Bacterial and mycobacterial infections are important problems associated with morbidity and mortality in lung transplant recipients. Comprehensive approaches starting at the time of transplant evaluation and continued through post-transplant periods are required to minimize the risk of infection and optimize the management of infectious complications.

\section{Acknowledgments}

Funding: None.

\section{Footnote}

Provenance and Peer Review: This article was commissioned by the Guest Editors (Masaaki Sato and Dong Tian) for the series "Strategies to Achieve Long-Term Success of Lung Transplantation" published in Annals of Translational Medicine. The article was sent for external peer review organized by the Guest Editors and the editorial office.

Conflicts of Interest: The series "Strategies to Achieve LongTerm Success of Lung Transplantation" was commissioned by the editorial office without any funding or sponsorship. The authors have no conflicts of interest to declare.

Ethical Statement: The authors are accountable for all aspects of the work in ensuring that questions related to the accuracy or integrity of any part of the work are appropriately investigated and resolved.

Open Access Statement: This is an Open Access article distributed in accordance with the Creative Commons Attribution-NonCommercial-NoDerivs 4.0 International License (CC BY-NC-ND 4.0), which permits the noncommercial replication and distribution of the article with the strict proviso that no changes or edits are made and the original work is properly cited (including links to both the formal publication through the relevant DOI and the license). See: https://creativecommons.org/licenses/by-nc-nd/4.0/.

\section{References}

1. International Report on Organ Donation and Transplantation Activities Executive summary 2017. Accessed December 9, 2019. Available online: http://www. transplant-observatory.org/who-ont/

2. Chambers DC, Yusen RD, Cherikh WS, et al. The Registry of the International Society for Heart and Lung Transplantation: Thirty-fourth Adult Lung And HeartLung Transplantation Report-2017; Focus Theme: Allograft ischemic time. J Heart Lung Transplant 2017;36:1047-59.

3. Rana A, Gruessner A, Agopian VG, et al. Survival benefit of solid-organ transplant in the United States. JAMA Surg 2015;150:252-9.

4. Zaas AK, Alexander BD. New developments in the diagnosis and treatment of infections in lung transplant recipients. Respir Care Clin N Am 2004;10:531-47.

5. Fishman JA. Infection in Organ Transplantation. Am J Transplant 2017;17:856-79.

6. Fishman JA. Infection in solid-organ transplant recipients. N Engl J Med 2007;357:2601-14.

7. Carlsen SE, Bergin CJ. Reactivation of tuberculosis in a donor lung after transplantation. AJR Am J Roentgenol 1990;154:495-7.

8. Winthrop KL, Kubak BM, Pegues DA, et al. Transmission of Mycobacterium tuberculosis via lung transplantation. Am J Transplant 2004;4:1529-33.

9. Mortensen E, Hellinger W, Keller C, et al. Three cases of donor-derived pulmonary tuberculosis in lung transplant recipients and review of 12 previously reported cases: opportunities for early diagnosis and prevention. Transpl Infect Dis 2014;16:67-75.

10. Cassir N, Delacroix R, Gomez C, et al. Transplanted lungs and the "white plague": A case-report and review of the literature. Medicine (Baltimore) 2017;96:e6173.

11. Speich R, van der Bij W. Epidemiology and management of infections after lung transplantation. Clin Infect Dis 2001;33 Suppl 1:S58-65.

12. Gagliotti C, Morsillo F, Moro ML, et al. Infections in liver and lung transplant recipients: a national prospective cohort. Eur J Clin Microbiol Infect Dis 2018;37:399-407.

13. Aguilar-Guisado M, Givalda J, Ussetti P, et al. Pneumonia after lung transplantation in the RESITRA Cohort: a multicenter prospective study. Am J Transplant 2007;7:1989-96.

14. Yun JH, Lee SO, Jo KW, et al. Infections after lung transplantation: time of occurrence, sites, and microbiologic etiologies. Korean J Intern Med 2015;30:506-14.

15. Kim SY, Shin JA, Cho EN, et al. Late respiratory infection after lung transplantation. Tuberc Respir Dis (Seoul) 2013;74:63-9. 
16. Maurer JR, Tullis DE, Grossman RF, et al. Infectious complications following isolated lung transplantation. Chest 1992;101:1056-9.

17. Horvath J, Dummer S, Loyd J, et al. Infection in the transplanted and native lung after single lung transplantation. Chest 1993;104:681-5.

18. Dulek DE, Mueller NJ. Pneumonia in solid organ transplantation: Guidelines from the American Society of Transplantation Infectious Diseases Community of Practice. Clin Transplant 2019;33:e13545.

19. Husain S, Chan KM, Palmer SM, et al. Bacteremia in lung transplant recipients in the current era. Am J Transplant 2006;6:3000-7.

20. Palmer SM, Alexander BD, Sanders LL, et al. Significance of blood stream infection after lung transplantation: analysis in 176 consecutive patients. Transplantation 2000;69:2360-6.

21. Gupta MR, Valentine VG, Walker JE, Jr., et al. Clinical spectrum of gram-positive infections in lung transplantation. Transpl Infect Dis 2009;11:424-31.

22. Shields RK, Clancy CJ, Minces LR, et al. Staphylococcus aureus infections in the early period after lung transplantation: epidemiology, risk factors, and outcomes. J Heart Lung Transplant 2012;31:1199-206.

23. Manuel O, Lien D, Weinkauf J, et al. Methicillin-resistant Staphylococcus aureus infection after lung transplantation: 5 -year review of clinical and molecular epidemiology. J Heart Lung Transplant 2009;28:1231-6.

24. Pereira MR, Rana MM. Methicillin-resistant Staphylococcus aureus in solid organ transplantationGuidelines from the American Society of Transplantation Infectious Diseases Community of Practice. Clin Transplant 2019;33:e13611.

25. Clancy CJ, Bartsch SM, Nguyen MH, et al. A computer simulation model of the cost-effectiveness of routine Staphylococcus aureus screening and decolonization among lung and heart-lung transplant recipients. Eur J Clin Microbiol Infect Dis 2014;33:1053-61.

26. Vos R, Vanaudenaerde BM, Geudens N, et al. Pseudomonal airway colonisation: risk factor for bronchiolitis obliterans syndrome after lung transplantation? Eur Respir J 2008;31:1037-45.

27. Botha P, Archer L, Anderson RL, et al. Pseudomonas aeruginosa colonization of the allograft after lung transplantation and the risk of bronchiolitis obliterans syndrome. Transplantation 2008;85:771-4.

28. Lechtzin N, John M, Irizarry R, et al. Outcomes of adults with cystic fibrosis infected with antibiotic-resistant
Pseudomonas aeruginosa. Respiration 2006;73:27-33.

29. Hadjiliadis D, Steele MP, Chaparro C, et al. Survival of lung transplant patients with cystic fibrosis harboring panresistant bacteria other than Burkholderia cepacia, compared with patients harboring sensitive bacteria. J Heart Lung Transplant 2007;26:834-8.

30. Pouch SM, Patel G. Multidrug-resistant Gram-negative bacterial infections in solid organ transplant recipients-

Guidelines from the American Society of Transplantation Infectious Diseases Community of Practice. Clin Transplant 2019;33:e13594.

31. Shoham S, Shah PD. Impact of multidrug-resistant organisms on patients considered for lung transplantation. Infect Dis Clin North Am 2013;27:343-58.

32. Haidar G, Philips NJ, Shields RK, et al. CeftolozaneTazobactam for the Treatment of MultidrugResistant Pseudomonas aeruginosa Infections: Clinical Effectiveness and Evolution of Resistance. Clin Infect Dis 2017;65:110-20.

33. Horcajada JP, Montero M, Oliver A, et al. Epidemiology and Treatment of Multidrug-Resistant and Extensively Drug-Resistant Pseudomonas aeruginosa Infections. Clin Microbiol Rev 2019. doi: 10.1128/CMR.00031-19.

34. Ahya VN, Doyle AM, Mendez JD, et al. Renal and vestibular toxicity due to inhaled tobramycin in a lung transplant recipient. J Heart Lung Transplant 2005;24:932-5.

35. Carillo C, Pecoraro Y, Anile M, et al. Colistin-based Treatment of Multidrug-resistant Gram-negative Bacterial Pulmonary Infections After Lung Transplantation. Transplant Proc 2019;51:202-5.

36. Suhling H, Rademacher J, Greer M, et al. Inhaled colistin following lung transplantation in colonised cystic fibrosis patients. Eur Respir J 2013;42:542-4.

37. Dubberke ER, Reske KA, Olsen MA, et al. Epidemiology and outcomes of Clostridium difficile infection in allogeneic hematopoietic cell and lung transplant recipients. Transpl Infect Dis 2018;20:e12855.

38. Cusini A, Beguelin C, Stampf S, et al. Clostridium difficile infection is associated with graft loss in solid organ transplant recipients. Am J Transplant 2018;18:1745-54.

39. Tsapepas DS, Martin ST, Miao J, et al. Clostridium difficile infection, a descriptive analysis of solid organ transplant recipients at a single center. Diagn Microbiol Infect Dis 2015;81:299-304.

40. Paudel S, Zacharioudakis IM, Zervou FN, et al. Prevalence of Clostridium difficile infection among solid organ transplant recipients: a meta-analysis of published studies. 
PLoS One 2015;10:e0124483.

41. Len O, Rodriguez-Pardo D, Gavalda J, et al. Outcome of Clostridium difficile-associated disease in solid organ transplant recipients: a prospective and multicentre cohort study. Transpl Int 2012;25:1275-81.

42. Lee JT, Kelly RF, Hertz MI, et al. Clostridium difficile infection increases mortality risk in lung transplant recipients. J Heart Lung Transplant 2013;32:1020-6.

43. Theunissen C, Knoop C, Nonhoff C, et al. Clostridium difficile colitis in cystic fibrosis patients with and without lung transplantation. Transpl Infect Dis 2008;10:240-4.

44. Revolinski SL, Munoz-Price LS. Clostridium difficile in Immunocompromised Hosts: A Review of Epidemiology, Risk Factors, Treatment, and Prevention. Clin Infect Dis 2019;68:2144-53.

45. Mullane KM, Dubberke ER. Management of Clostridioides (formerly Clostridium) difficile infection (CDI) in solid organ transplant recipients: Guidelines from the American Society of Transplantation Community of Practice. Clin Transplant 2019;33:e13564.

46. Luong ML, Sareyyupoglu B, Nguyen MH, et al. Lactobacillus probiotic use in cardiothoracic transplant recipients: a link to invasive Lactobacillus infection? Transpl Infect Dis 2010;12:561-4.

47. Peleg AY, Husain S, Qureshi ZA, et al. Risk factors, clinical characteristics, and outcome of Nocardia infection in organ transplant recipients: a matched case-control study. Clin Infect Dis 2007;44:1307-14.

48. Santos M, Gil-Brusola A, Morales P. Infection by Nocardia in solid organ transplantation: thirty years of experience. Transplant Proc 2011;43:2141-4.

49. Poonyagariyagorn HK, Gershman A, Avery R, et al. Challenges in the diagnosis and management of Nocardia infections in lung transplant recipients. Transpl Infect Dis 2008;10:403-8.

50. Husain S, McCurry K, Dauber J, et al. Nocardia infection in lung transplant recipients. J Heart Lung Transplant 2002;21:354-9.

51. Singh N, Husain S. Infections of the central nervous system in transplant recipients. Transpl Infect Dis 2000;2:101-11.

52. Restrepo A, Clark NM. Nocardia infections in solid organ transplantation: Guidelines from the . Clin Transplant 2019;33:e13509.

53. Dromer C, Nashef SA, Velly JF, et al. Tuberculosis in transplanted lungs. J Heart Lung Transplant 1993;12:924-7.

54. Schulman LL, Scully B, McGregor CC, et al.
Pulmonary tuberculosis after lung transplantation. Chest 1997;111:1459-62.

55. Kesten S, Chaparro C. Mycobacterial infections in lung transplant recipients. Chest 1999;115:741-5.

56. Roman A, Bravo C, Levy G, et al. Isoniazid prophylaxis in lung transplantation. J Heart Lung Transplant 2000;19:903-6.

57. Malouf MA, Glanville AR. The spectrum of mycobacterial infection after lung transplantation. Am J Respir Crit Care Med 1999;160:1611-6.

58. Morales P, Briones A, Torres JJ, et al. Pulmonary tuberculosis in lung and heart-lung transplantation: fifteen years of experience in a single center in Spain. Transplant Proc 2005;37:4050-5.

59. Bravo C, Roldan J, Roman A, et al. Tuberculosis in lung transplant recipients. Transplantation 2005;79:59-64.

60. Torre-Cisneros J, Doblas A, Aguado JM, et al. Tuberculosis after solid-organ transplant: incidence, risk factors, and clinical characteristics in the RESITRA (Spanish Network of Infection in Transplantation) cohort. Clin Infect Dis 2009;48:1657-65.

61. Subramanian AK, Theodoropoulos NM. Mycobacterium tuberculosis infections in solid organ transplantation: Guidelines from the . Clin Transplant 2019;33:e13513.

62. Abad CLR, Razonable RR. Donor derived Mycobacterium tuberculosis infection after solid-organ transplantation: A comprehensive review. Transpl Infect Dis 2018;20:e12971.

63. Guirao-Arrabal E, Santos F, Redel J, et al. Efficacy and safety of short-term treatment with isoniazid and rifampicin for latent tuberculosis infection in lung transplant candidates. Clin Transplant 2017. doi: 10.1111/ ctr. 12901.

64. Chandrashekaran S, Escalante P, Kennedy CC. Mycobacterium abscessus disease in lung transplant recipients: Diagnosis and management. J Clin Tuberc Other Mycobact Dis 2017;9:10-8.

65. Huang HC, Weigt SS, Derhovanessian A, et al. Nontuberculous mycobacterium infection after lung transplantation is associated with increased mortality. J Heart Lung Transplant 2011;30:790-8.

66. Knoll BM, Kappagoda S, Gill RR, et al. Non-tuberculous mycobacterial infection among lung transplant recipients: a 15-year cohort study. Transpl Infect Dis 2012;14:452-60.

67. Shah SK, McAnally KJ, Seoane L, et al. Analysis of pulmonary non-tuberculous mycobacterial infections after lung transplantation. Transpl Infect Dis 2016;18:585-91.

68. Osmani M, Sotello D, Alvarez S, et al. Mycobacterium abscessus infections in lung transplant recipients: 15-year 
experience from a single institution. Transpl Infect Dis 2018;20:e12835.

69. Doucette K, Fishman JA. Nontuberculous mycobacterial infection in hematopoietic stem cell and solid organ transplant recipients. Clin Infect Dis 2004;38:1428-39.

70. George IA, Santos CA, Olsen MA, et al. Epidemiology and Outcomes of Nontuberculous Mycobacterial Infections in Solid Organ Transplant Recipients at a Midwestern Center. Transplantation 2016;100:1073-8.

71. Longworth SA, Vinnard C, Lee I, et al. Risk factors for nontuberculous mycobacterial infections in solid organ transplant recipients: a case-control study. Transpl Infect Dis 2014; 16:76-83.

72. Fan MH, Hadjiliadis D. Incidence and management of mycobacterial infection in solid organ transplant recipients. Curr Infect Dis Rep 2009;11:216-22.

73. Griffith DE, Aksamit T, Brown-Elliott BA, et al. An official ATS/IDSA statement: diagnosis, treatment, and prevention of nontuberculous mycobacterial diseases. Am J Respir Crit Care Med 2007;175:367-416.

74. Longworth SA, Daly JS. Management of infections due to nontuberculous mycobacteria in solid organ transplant recipients-Guidelines from the American Society of Transplantation Infectious Diseases Community of Practice. Clin Transplant 2019;33:e13588.

75. Haworth CS, Banks J, Capstick T, et al. British Thoracic Society Guideline for the management of non-tuberculous mycobacterial pulmonary disease (NTM-PD). BMJ Open Respir Res 2017;4:e000242.

76. Malinis M, Boucher HW. Screening of donor and candidate prior to solid organ transplantation-Guidelines from the American Society of Transplantation Infectious Diseases Community of Practice. Clin Transplant 2019;33:e13548.

77. Ramos KJ, Smith PJ, McKone EF, et al. Lung transplant referral for individuals with cystic fibrosis: Cystic Fibrosis Foundation consensus guidelines. J Cyst Fibros 2019;18:321-33.

78. Weill D, Benden C, Corris PA, et al. A consensus document for the selection of lung transplant candidates: 2014--an update from the Pulmonary Transplantation Council of the International Society for Heart and Lung Transplantation. J Heart Lung Transplant 2015;34:1-15.

79. Mattner F, Fischer S, Weissbrodt H, et al. Post-operative nosocomial infections after lung and heart transplantation. J Heart Lung Transplant 2007;26:241-9.

80. Abid Q, Nkere UU, Hasan A, et al. Mediastinitis in heart and lung transplantation: 15 years experience. Ann Thorac
Surg 2003;75:1565-71.

81. Shields RK, Clancy CJ, Minces LR, et al. Epidemiology and outcomes of deep surgical site infections following lung transplantation. Am J Transplant 2013;13:2137-45.

82. Anesi JA, Blumberg EA, Abbo LM. Perioperative Antibiotic Prophylaxis to Prevent Surgical Site Infections in Solid Organ Transplantation. Transplantation 2018;102:21-34.

83. Abbo LM, Grossi PA. Surgical site infections: Guidelines from the American Society of Transplantation Infectious Diseases Community of Practice. Clin Transplant 2019;33:e13589.

84. Campos S, Caramori M, Teixeira R, et al. Bacterial and fungal pneumonias after lung transplantation. Transplant Proc 2008;40:822-4.

85. Bratzler DW, Dellinger EP, Olsen KM, et al. Clinical practice guidelines for antimicrobial prophylaxis in surgery. Am J Health Syst Pharm 2013;70:195-283.

86. Steinberg JP, Braun BI, Hellinger WC, et al. Timing of antimicrobial prophylaxis and the risk of surgical site infections: results from the Trial to Reduce Antimicrobial Prophylaxis Errors. Ann Surg 2009;250:10-6.

87. Fishman JA, Gans H. Pneumocystis jiroveci in solid organ transplantation: Guidelines from the American Society of Transplantation Infectious Diseases Community of Practice. Clin Transplant 2019;33:e13587.

88. Rubin LG, Levin MJ, Ljungman P, et al. 2013 IDSA clinical practice guideline for vaccination of the immunocompromised host. Clin Infect Dis 2014;58:e44-100.

89. Danziger-Isakov L, Kumar D. Vaccination of solid organ transplant candidates and recipients: Guidelines from the American society of transplantation infectious diseases community of practice. Clin Transplant 2019;33:e13563.

90. Miyairi I, Funaki T, Saitoh A. Immunization practices in solid organ transplant recipients. Vaccine 2016;34:1958-64.

91. Rosen J. Travel medicine and the solid-organ transplant recipient. Infect Dis Clin North Am 2013;27:429-57.

92. Avery RK, Michaels MG. Strategies for safe living following solid organ transplantation-Guidelines from the American Society of Transplantation Infectious Diseases Community of Practice. Clin Transplant 2019;33:e13519.

Cite this article as: Okamoto K, Santos CAQ. Management and prophylaxis of bacterial and mycobacterial infections among lung transplant recipients. Ann Transl Med 2020;8(6):413. doi: 10.21037/atm.2020.01.120 